\author{
13 th INTERNATIONAL CONFERENCE \\ "STANDARDIZATION, PROTYPES AND QUALITY: \\ A MEANS OF BALKAN COUNTRIES' COLLABORATION"
}

Transilvania University of Brasov, Romania

Brasov, Romania, November 3 - 4, 2016

\title{
Conceptual and Methodological Aspects of Documenting the History and the Future of Monuments Restoration - Towards an Interdisciplinary Perspective
}

\author{
ZACHAROPOULOU Georgia \\ Ministry of Culture, Ephorate of Antiquities, Thessaloniki, Greece, gzacharopoulou@culture.gr \\ "In memory of my mother"
}

\begin{abstract}
The objective of the paper is the methodological presentation of the basic principles towards a critical interdisciplinary approach for studying the history of monuments restoration, valid for different cultures.

The proposed integrated framework offers the possibility to study and document monuments restoration in various spatial levels e.g. global, continental, international, national, regional, and local. The conceptual and methodological aspects are based on the following fundamental pillars a) the development of science and technology, including relevant history of education, b) the evolution of the restoration philosophy, c) the incorporation of the above in restoration projects at a lower level, d) the infiltration of the above in restoration interventions at the lowest level.

The author expects that the above successive and/or parallel levels of scientific branches can contribute effectively to the analysis, synthesis and comparative assessment of the aspects and criteria that influenced monuments restoration timeline. The challenge for the researcher of the monuments restoration history is the adjustment of the whole process to his own -under research- level in such a way as to take advantage of all the interdisciplinary inputs creating, thus, inventive links and stimulating new information and knowledge. The above are briefly tested in the case study of Thessaloniki, Macedonia, Greece.

Such an inductive approach will enable all disciplines to devote their finest efforts towards understanding, documenting and studying monuments restoration history and, thus, support effectively a sustainable future for the world's cultural heritage.
\end{abstract}

\section{Keywords}

interdisciplinary, inductive reasoning, restoration philosophy, science and technology, monuments restoration

\section{Introduction}

In reviewing the literature on monuments restoration philosophy and practice, it derives that it has historically been an area under consideration and debate of the so-called Western world, principally Europe [1]. Gradually, this 'continental' perception was increasingly challenged by a range of Western and non-Western interest groups. Although a variety of continuing local, regional, national etc. cultures around the world have developed a different perspective in interpreting and conserving their heritage based on alternative ways of thinking, quite a few decades had to pass before their viewpoint in restoration issues was officially acknowledged [2].

Since 2010, Critical Heritage Studies (CHS) are emerging as a challenging area of critical enquiry [3] accepting that "the old way of looking at heritage -the Authorised Heritage Discourse (AHD)- privileges old, grand, prestigious, expert approved sites, buildings and artefacts that sustain Western narratives of nation, class and science" [4]. It is also suggested that "archaeology, as a discipline, can no longer assume to hold all the answers" and further that experts in archaeology, history, architecture and art history, finally sustain a limited idea of what heritage is and how it should be studied and managed [4]. A wider range of disciplines including sociology, anthropology, political science etc are actively involved. The 
outcome of such a critical process should be a matter of a continuing -certainly not exclusive- debate.

Regarding the "dialectic" of restoration and conservation of "material substance", a number of principles and official recommendations have gradually been developed -not without conflicts- still leaving the issue open. After the French revolution, the "traditional way" of understanding the past which acknowledged the "use" value of outstanding constructions with "memorial" or "symbolic universal" value much more than their "material substance"- was left behind [5]. "The desire to protect and restore national monuments as concrete evidence of a nation's history" became dominant, as nationalism and romanticism were progressively evolved in European countries. Until now, the complexity of technical concerns and the cultural character of the problem, keep demonstrating "the need for maturity and proper historic consciousness" [5].

Focusing on the study of monuments restoration history, a lack of inter/multi/cross/disciplinarity has been persistently evidenced, in every case. Recognizing that "disciplinary research often fails to describe the whole picture", "the need to address complex problems with equally complex knowledges while, simultaneously, avoiding excluding the contribution of the alternative knowledges of those who are directly embedded in the issue" becomes imperative [6].

The author seeks to contribute towards documenting the history and the future of monuments restoration with emphasis on their -so questioned lately- materiality (tangible dimension); intangible values might also be included. Hence, the paper will be confined in structural (science and technology of structures) and architectural conservation (restoration philosophy) thematic.

It is argued that adopted structural solutions, both in their initial concept (geometric, symbolic or construction-oriented) and restoration interventions, have a potential to form a manageable database for scientific research and critical interpretation. In this frame, fundamental conceptual and methodological interrelated aspects need to be established, evolved and refined on an interdisciplinary inductive reasoning. The present paper is focused on the methodology rather than the outcomes of such a process.

\section{Integrated Approach in 'Scale' vs. 'Criteria'}

The proposed inductive process comprises a) a review of the global/continental/ international experience on related discipline aspects (state-of-the-art), b) similarly, a review of the national/regional/local understanding (state-of-the-art), c) their comparative study and finally, d) critical conclusions should be addressed - even as a working hypotheses that require further enquiry. The above steps should be initially defined geospatially and repeated per characteristic development period; scale of place, scale of time [7].

Accordingly, the classification approach (criteria) may not remain firm but vary according to time. For that reason, the evaluation of the heritage values -"subjectively" or "objectively" perceived- is a matter of an ongoing process, in which as many disciplines as possible should participate [7].

Disciplinary expertise "provides the structure and legitimacy to the integrated research process" and should be acknowledged and differentiated from integrated research [6]. Bearing in mind that "under the umbrella of integrated research an inexhaustive list of terminologies is used to define the concept, including: collaborative, integral, integrated, complementary, combined, participatory, transepistemic, system-oriented, transprofessional, comprehensive, problem oriented, cross-boundary, holistic, multidisciplinary, crossdisciplinary, interdisciplinary, and transdisciplinary" [6], a fundamental methodological dilemma emerges for further consideration: a) "the less rigorous the outline of the research process the more difficult the research will be conduct (and therefore the possibility of a lower quality result emerges) but, b) if the outline is too flexible, the research process will not be able to deal sufficiently with the complexity of the system and therefore, again, the research quality is likely to decline" [6].

In the long run, the key question persists: How integrated approach will influence understanding, documenting and studying monuments restoration history in support to a sustainable future for the world's cultural heritage? An integrated approach requires a comprehensive and appropriate identification in terms of content, scale and context in order to deliver consistent results [7].

Such a detailed effort, however, is beyond the purpose of the present paper as defined above. 


\section{Conceptual and Methodological Aspects towards an Interdisciplinary Approach}

Regarding international and Greek literature, the following alternative taxonomies are accepted:

A) Based on the "science and technology" criterion vs. social \& economic sciences i) the "pre-industrial" era to $\mathrm{C} 17$, ii) the period of the "first and second industrial revolution" (C18-mid C19 and mid C19mid C20 respectively) and iii) the "post-industrial" era (mid C20-C21) [7].

B) Based on the "restoration philosophy" criterion i) "romantic restoration", the common approach of monuments aiming at the purity of form, established in Renaissance and developed mainly in C19 (Schinkel, Scott, Merimèe, Viollet-le-Duc), ii) "conservation movement", with emphasis on material authenticity and documentary value of the monument, C19 (Ruskin, Morris, Boito), and iii) "modern conservation theory" or "scientific conservation", based on a critical historical evaluation of a monument in its aesthetic, historical and use values, C19-C20 (Riegl, Argan, Brandi) [5]. Generally, this categorization embraces both tangible (i.e. "material substance") and intangible (e.g. embedded know-how) dimension of heritage and is shaped by diverse human interests, rather than standing objectively independent from these interests. In the current transitive period of the beginning of C21, it seems that any competing notions and/or actions require rethinking and redefinition -after analysis, synthesis and comparative assessment- as a prerequisite in order to create multiple inventive links and pluralistic new knowledge in monuments restoration theory and practice.

C) Based on the "scale" criterion e.g. in Greece, the following characteristic periods are defined i) the "classicism" period (1833-1884) -from the establishment of the Modern Greek State to the founding of the Christian Archaeological Society (XAE, in Greek), in 1885, ii) "scientific approach" of monuments (1885-1909) -founding of XAE to the 'Goudi insurrection' of 1909, and iii) the period "between WWI and WWII" [8, 9], followed by iv) the "post war" period (mid C20-C21).

Moving from the incorporation of the above mentioned in restoration projects at a national level (e.g. Greece) $[8,9]$, towards their infiltration in monuments restoration interventions at a region/local scale (e.g. Macedonia/Thessaloniki), the research becomes much more challenging indeed. The case study of Thessaloniki is characteristic in demonstrating that. It is evident that Greece's periodization system regarding monuments restoration does not entirely harmonize to the city's case, as Thessaloniki was under Ottoman rule from 1430 up to 1912.

\section{The Case Study of Thessaloniki, Greece}

The revised "scale" criterion e.g. Thessaloniki, identifies the following periods i) from the founding of the city, in 316/315BC -then roman 148BC, byzantine 330AC, Ottoman 1430AC- to the proclamation of the Ottoman reforms, in 1839, ii) the years between the proclamation of the Ottoman reforms and the termination of Ottoman rule $(1839$ - 1912) and iii) the first decades of the Greek administration "between WWI and WWII" (1912 - 1939) [8, 9], followed by iv) the "post war" period.

Diachronically [7], Thessaloniki was a key port, as well as a commercial and cultural crossroad. Networks, within and outside the Ottoman Empire, facilitated the distribution of products, developments and ideas. The export trade was conducted mostly by caravans through the Balkan Peninsula or by commercial ships through maritime routes to Mediterranean ports, mainly Marseille and Livorno, as well as to other European destinations: Great Britain, the Netherlands, the Austrohungarian Empire, the German and Scandinavian States, Poland and Russia. The interest of the European "Great Powers" to extend free market was indicated by their efforts to control the land and water roots, constructing significant infrastructure works. In 1888, the railway lines allowed the connection of Thessaloniki and Constantinople with the European network. In 1904, the construction of the modern port of Thessaloniki was completed.

Northern Greece's incorporation to the Greek State resulted as a consequence of the Balkan Wars (1912-13). During World War I (1914-18), Greece jointed the Triple Entente alliance (Great Britain, France, and Russia), in 1917 -a year that a great fire destroyed the historic city center. After Greece's defeat in Asia Minor (1922), a massive exchange of population between Greece and Turkey occurred. Greece suffered severely by the Word War II followed by the occupation of the country (1941-44) by the Germans, Italians and Bulgarians and the following civil war (1945-49). During the period 19671974 , a military junta was imposed on the country by colonel regime. After the restoration of democracy (1974), Greece joined the European Union (1980) and entered the Eurozone (2002). Soon afterwards 
RECENT, Vol. 17, no. 3(49), November, 2016

followed the global recession (2008) and the explosion of the Greece's debt crisis (2009).

Through centuries, Thessaloniki's monuments have survived great ( $>6$ Richter scale) earthquakes (in 620,1420-30, 1677, 1759, 1932, 1978AC) and fires. Restoration works were undertaken based on the approved needs, beliefs and values, as well as the level of science and technology of each epoch.

Summarizing, Thessaloniki's rich cultural heritage -mainly byzantine churches [10] most of which had been transformed to mosques by the Ottomans after the city's conquest, in 1430- was remained underestimated and underprotected by the defeaters. In late C19, Thessaloniki's byzantine monuments were increasingly admired and studied primarily by the Archeological branches of France and Great Britain; direct influences from Europe and indirect from Greece can be observed and further studied. The growing pressure of the European scientific world and also the desire of the Ottomans to be modernized had permitted restoration works on former byzantine churches -then mosques. Before 1912, romantic restoration approach was dominated -mostly concerning eclectical interventions on the exteriors- as the principles of the scientific restoration (typically 1883, C. Boito) were not widely approved yet. Additionally, the high aesthetic and historic quality of the revealed mosaics and wall paintings of the interior of the byzantine monuments was greatly appreciated by the related disciplines; as a result the interventions never stopped [11]. Many of the ongoing restoration projects continued after 1912 under the responsibility of the Greek State and then, direct influences from Greece and indirect from Europe can be traced. Last decades, Europe plays a part in shaping the future of the conservation of the Greek cultural heritage, as the majority of the ongoing conservation projects are cofinanced by the National Strategic Reference Framework.

Key questions are emerging, concerning the construction know-how and the building materials that restoration practice diachronically used -before and during conservation theory development and incorporation in a local scale. It is also known that the industrial revolution triggered tremendous changes in every socio-political and economic domain [7]. The parallel study of science and technology history, including relevant education evolution, should fill the research gap with the aim to provide answers and proposals on the appropriate methods and materials for future effective interventions.

All research steps are essential towards this aim; either working within a single discipline (intradisciplinary approach), or viewing one discipline from the perspective of another (crossdisciplinary), or working together but each different discipline drawing on their disciplinary knowledge (multidisciplinary), or integrating knowledge and methods from different disciplines achieving a real synthesis of approaches and new knowledge (interdisciplinary), and/or creating a unity of intellectual frameworks beyond the disciplinary perspectives (transdisciplinary). Transdisciplinarity is the most desirable form of integrated research -albeit difficult to obtain; "some researchers are, in fact, skeptical about whether it can be achieved at all" [6]. As "interdisciplinary studies focus on addressing specific 'real world' system problems" [6], interdisciplinarity is suggested here as the most pragmatic target.

Models and modelling have a long history in science and engineering. It is accepted -though it still needs more documentation- that ancient structures have been designed according to key empirical rules based on few comprehensive mechanical principles; however, their efficiency has been tested by time itself through severe natural disasters. Detailed interdisciplinary research on the monuments of Thessaloniki (mainly UNESCO World Heritage) - based on the multi-layered criteria of Fig. 1 - will provide additional data e.g. i) on the potential geometrical, symbolic, structural, architectural, and/or art protypes of the city constructions, ii) on the evolution of the structural systems and their 'secret' relationships with the city monuments, iii) on the values of design (original or restorative) and the new technical accomplishments, as a part of the world's construction history, iv) on the multiple interactions through the trade distribution (economic and enterprise history [12]) of construction products, technical developments and even patents, because of the city's key position on the map and v) on the successful -or not- restoration works throughout centuries, as an invaluable tool for future rational decisions in support of a sustainable future for the world's cultural heritage, etc.

Within this inductive research process, cohesive outcomes are already growing.

From the ongoing research, it seems that Greece -and Thessaloniki- are always aware about any innovative technical achievements; further, it can be argued that Greece has co-shaped Western theory 
and practice bearing in mind the restoration process of ancient monuments in Athens, in late C19-C20 $[8,9]$. Gradually, conservation principles were also implemented on the restoration works of the Thessaloniki's byzantine monuments that are of great significance. The proposed conceptual model of an integrated approach in the city's monuments restoration is summarized in Figure 1. Such a model might reveal the power relations as the most influential factor in conservation history.

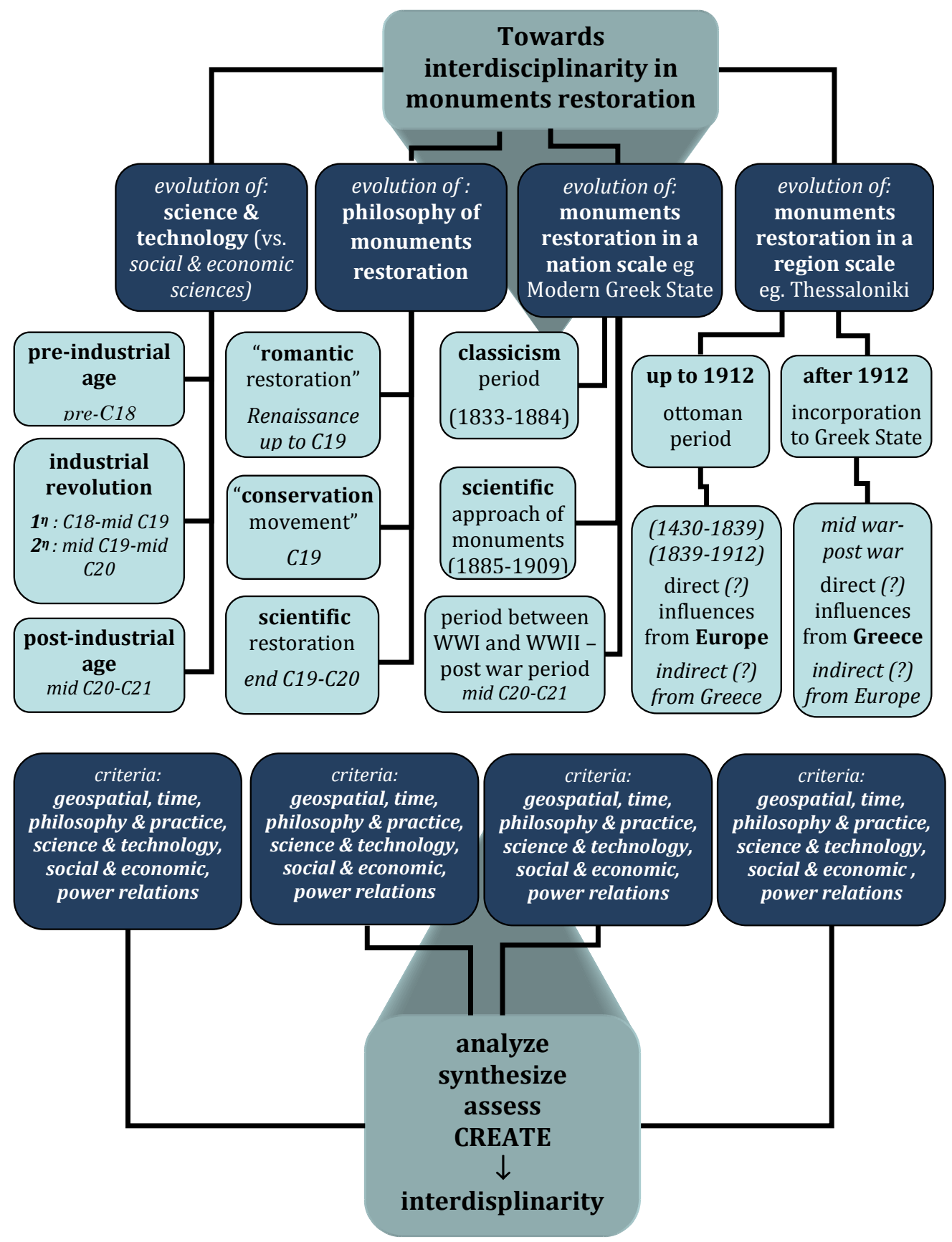

Fig. 1. Conceptual model of an integrated approach in monuments restoration - The case study of Thessaloniki, GR

\section{Conclusion}

Monuments restoration philosophy and practice has historically been developed in the so-called Western world on the basis of nation and science, with emphasis on the concept of material heritage's authenticity. Although this perception has been challenged by a range of Western and non-Western 
interest groups, the outcome of the ongoing critical enquiry should be a matter of a continuing -certainly not exclusive - debate; and, in principal, political in nature.

The conceptual and methodological aspects of an integrated research for studying the history of monuments restoration, valid for different cultures, are better outlined in the frame of an interdisciplinary inductive reasoning. The proposed integrated conceptual framework offers the possibility to study and document monuments restoration in various spatial levels, involving a wider range of disciplines -such as philosophy, history, archaeology, architecture, art history, education history, sociology, anthropology, economic and political science etc. All of them can devote their finest efforts to the analysis, synthesis and comparative assessment of the issues and -dynamically evolvedcriteria that influenced monuments restoration timeline with the aim to create authentic links and innovative knowledge. The above have been briefly demonstrated in the case study of Thessaloniki's monuments in Northern Greece.

Such a perspective will facilitate not only the contribution and acting together of as many disciplines are possible but also the participation of ordinary people, through social action, towards a democratic management of a sustainable future for the world's cultural heritage - our heritage as a matter of fact.

\section{References}

1. *** (1964): International charter for the conservation and restoration of monuments and sites (The Venice Charter 1964). II ${ }^{\text {nd }}$ International Congress of Architects and Technicians of Historic Monuments, Venice, 1964. http://www.icomos.org/charters/venice_e.pdf

2. Larsen, K.E. (Editor) (1994): Nara Conference on authenticity in relation to the World Heritage Convention... Proceedings. Tapir Publ., ISBN 82-519-1416-7

3. Association of Critical Heritage Studies (ACHS). http://www.criticalheritagestudies.org/history. Accessed: 2016-05-20

4. Waterton, E., Smith, L. (2009): There is no such thing as heritage. In: Taking Archaeology out of Heritage, p. 1027, Cambridge Scholars Publishing, ISBN (10): 1-4438-1442-3, ISBN (13): 978-1-4438-1442-3, Newcastle upon Tyne, UK

5. Jokilehto, J. (1986): A History of Architectural Conservation. The Contribution of English, French, German and Italian Thought towards an International Approach to the Conservation of Cultural Property. D. Phil Thesis, IoAAS, University of York, UK, p. 7-9

6. Stock, P., Burton, R.J.F. (2011): Defining Terms for Integrated (Multi-Inter-Trans-Disciplinary) Sustainability Research. Sustainability, ISSN 2071-1050, Vol. 3, p. 1090-1111. DOI:10.3390/su3081090

7. Zacharopoulou, G. (2011): Diachronic exploitation of landscape resources - tangible and intangible industrial heritage and their synthesis suspended step. Proceedings of the XVI ${ }^{\text {th }}$ International TICCIH Congress 2015: Industrial Heritage in the Twenty-First Century, New Challenges, Lille, 6-11 September 2015. https://ticcih2015.sciencesconf.org/) (forthcoming)

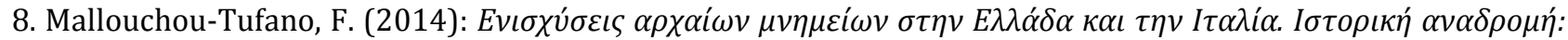

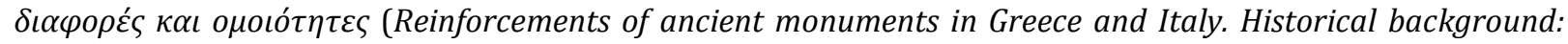

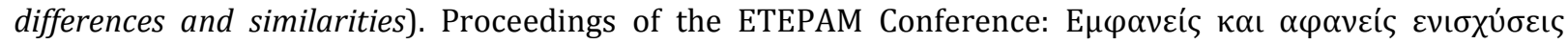
$\mu \nu \eta \mu \varepsilon i ́ \omega \nu$ (Visible and invisible monuments' reinforcements), 2014-10-10, Thessaloniki, Greece (in Greek). http://www.etepam.gr/

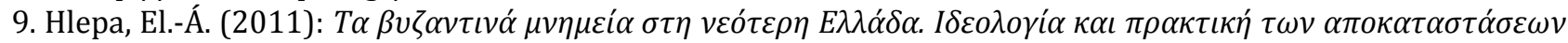
1833-1939 (The Byzantine monuments in modern Greece. Ideology and practice of restorations (1833-1939)). Ed. Kapon, ISBN 978-960-6878-38-1

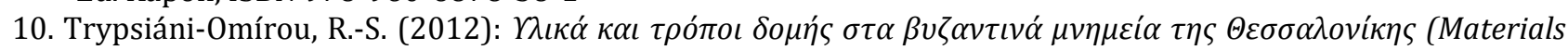
and construction ways in the byzantine monuments of Thessaloniki). PhD Thesis, Auth, Thessaloniki, Greece (in Greek). http://hdl.handle.net/10442/hedi/30500

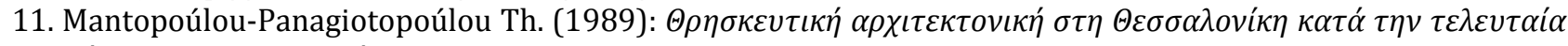

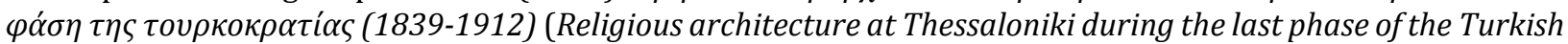
occupation (1839-1912)). Churches-synagogues-mosques. PhD Thesis, Auth, Thessaloniki, Greece (in Greek). DOI:10.12681/eadd/1163

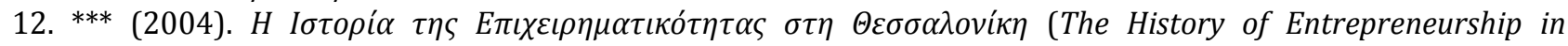
Thessaloniki). Vol. A'-D'. Ed. П.E.E.B.E., ISBN 960-86752-3-5 (set), Thessaloniki, Greece (in Greek). https://www.peebe.gr/publications/istoria-tis-epichirimatikotitas-stin-thessaloniki-2/ 